\title{
SIMONE MALDONADO E SEU LEGADO À ANTROPOLOGIA DA PESCA
}

\author{
Maristela Oliveira de Andrade ${ }^{1}$ \\ iD https://orcid.org/0000-0001-7393-3977 \\ Rubens Elias da Silva ${ }^{2}$ \\ iD https://orcid.org/0000-0002-6704-6367 \\ Francisca de Souza Miller ${ }^{3}$ \\ iD https://orcid.org/0000-0002-1427-2723
}

\begin{abstract}
RESUMO
O reconhecimento do lugar ocupado por antropólogas e antropólogos em instituições universitárias nordestinas, para dar visibilidade às suas contribuições ao pensamento antropológico, constitui o propósito deste ensaio, que elegeu Simone Carneiro Maldonado e seu legado à antropologia da pesca para compor o rol dos pioneiros da pesquisa antropológica no âmbito institucional regional. Dito isto, o presente texto articula como a antropóloga adentrou o campo e como as relações sociais foram permeadas por mediações entre a identidade de si e a identidade dos outros, cujo resultado foi uma intensa e rica contribuição para o campo etnográfico no Nordeste. Este ensaio se caracteriza como um exercício de memória de três autores que conviveram de diferentes maneiras com esta pesquisadora ao longo da sua trajetória acadêmica, para retratar os passos que ela tomou em sua longa experiência etnográfica na construção da antropologia da pesca.
\end{abstract}

Palavras-chave: Pescadores do Mar, Trajetória Intelectual, Gênero, Nordeste.

\section{SIMONE MALDONADO AND HER LEGACY TO FISHING ANTHROPOLOGY}

\begin{abstract}
The recognition of the place anthropologists occupy in the northeastern university institutions to lend visibility to their contributions to anthropological thoughts is the main aim of this paper which chose Simone Carneiro Maldonado and her legacy to fishing anthropology to be part of the list of anthropological research pioneers in the regional institutional scope. Having said that, this paper articulates how the anthropologist joined this field and how the social relations were pervaded between her own identity and that of others, whose result was an intense and rich contribution to the ethnographic area in the northeast. This paper is defined as a memory exercise of the three authors who have shared experiences with this researcher in many ways along her academic life to depict the steps, she took on her long ethnographic experience in the building of fishing anthropology.
\end{abstract}

Keywords: Sea Fishermen, Intellectual Trajectory, Gender, Northeast.

\section{SIMONE MALDONADO Y SU LEGADO A LA ANTROPOLOGÍA DE PESCA}

\section{RESUMEN}

\footnotetext{
${ }^{1}$ Professora titular aposentada e voluntária no programa de pós-graduação em antropologia PPGA da UFPB. Coordenadora adjunta. Grupo interdisciplinar de pesquisa em cultura, sociedade e ambiente GIPCSA. E-mail: andrademaristela@ hotmail.com.

${ }^{2}$ Pós-Doutor em Ciências das Religiões pela Université du Québec à Montreal (2019). Doutor em Sociologia pelo PPGS - UFPB. Professor adjunto do CFI da Ufopa, Santarém, vinculado aos Programas de Pós-Graduação em Ciências da Sociedade (PPGCS) e Sociedade, Ambiente e Qualidade de Vida (PPGSAQ), nesta IES. Coordenador do Núcleo de Pesquisa em Socioantropologia da Pesca no Baixo Amazonas (NUPEAM). E-mail: hellazer09@gmail.com.

${ }^{3}$ Professora associada IV do Departamento de Antropologia e da Pós-Graduação em Antropologia Social PPGAS. Coordenadora do Grupo de Pesquisa Etnologia, Tradição, Ambiente e Pesca Artesanal ETAPA. UFRN. Pós-Doutor(a) em Antropologia pela Universidade de Lisboa-Portugal. E-mail: fransmiller56@ yahoo.com.br.
} 
El reconocimiento del lugar ocupado por antropólogos y antropólogas en instituciones universitarias del noreste para dar visibilidad a sus contribuciones al pensamiento antropológico constituye el propósito de este ensayo que ha elegido Simone Carneiro Maldonado y su legado a la Antropología de pesca para componer lista de los pioneros de la pesquisa antropológica en el ámbito institucional regional. Dicho esto, este texto articula como la antropóloga adentró a ese campo y como las relaciones sociales fueron permeadas por mediaciones entre su identidad y la de los otros cuyo resultado fue una intensa y rica contribución para el campo etnográfico de Noreste. Este trabajo se caracteriza como un ejercicio de memoria de tres autores que convivieron de diferentes maneras con esta investigadora a lo largo de su trayectoria académica para describir los pasos que siguió en su larga experiencia etnográfica en la construcción de la antropología de pesca.

Palabras clave: Pescadores del Mar, Trayectoria Intelectual, Género, Noreste.

\section{INTRODUÇÃO}

Neste dossiê organizado por Mércia Batista e Rita de Cássia Santos há uma oportunidade valiosa de prestarmos reconhecimento e homenagem ao legado deixado por antropólogas de instituições nordestinas que deram uma contribuição muito relevante em diferentes campos da antropologia. Mesmo atuando em instituições fora do circuito dos grandes centros de produção de conhecimento antropológico do Brasil, elas deram uma contribuição marcante, conseguindo transpor as fronteiras regionais.

O interesse de participar deste espaço de memória da institucionalização do campo antropológico, na Região Nordeste, foi motivado pelo reconhecimento do pioneirismo da contribuição da antropóloga Simone Maldonado no tocante à antropologia da pesca ou antropologia marítima. Por outro lado, o intuito foi de compartilhar diferentes experiências e sentimentos em relação à trajetória dela, a partir de diferentes olhares e posições. Para abordar a memória institucional relativa ao ambiente acadêmico no qual Simone desenvolveu seu ofício de docente/pesquisadora, faremos uma breve descrição da área de antropologia do Departamento de Ciências Sociais - DCS, do Campus I da UFPB, depois de 1991, que tinha apenas seis docentes (Aécio Vilar de Aquino; Franz Moonen; Maria Otília Storni; Simone Maldonado, Theophilos Rifiotis e Maristela Andrade). Esses docentes atuavam em áreas bem distintas, com destaque para os dois que foram mais fiéis a seus objetos de estudo: Moonen, que se dedicava às minorias étnicas de indígenas e ciganos; e Simone, ao estudo dos pescadores do mar. Este grupo de docentes ministrava disciplinas de antropologia em diferentes cursos de graduação, já que o DCS, em 1991, não tinha criado ainda sua graduação em ciências sociais. As disciplinas da área de Antropologia eram demandadas por cursos da área das Ciências Humanas (Serviço Social; História; Psicologia; Comunicação) e das Ciências da Saúde (Medicina, Enfermagem, Odontologia, Nutrição). Havia uma cooperação com a área de sociologia na oferta de disciplinas dessa área. A unidade acadêmica ligada ao DCS na época era o Mestrado em Ciências Sociais - MCS, criado em 1979, que acolhia professores da área de antropologia que integravam seu corpo docente, ao lado de professores das áreas de sociologia e ciência política. 
O MCS, assim como o DCS, possuíam áreas de antropologia que se constituíam espaços acadêmicos e institucionais que congregavam esses professores e permitia uma interação, ainda que limitada, já que não havia uma cooperação contínua em atividades acadêmicas e pesquisas comuns. Apesar das limitações, a área de antropologia do MCS organizou com sucesso, em 1995, a IV Reunião Norte e Nordeste de Antropologia - ABANNE, na UFPB, que reuniu um grande número de participantes. Além disso, a área teve uma revista criada em 1987 e organizada por Franz Moonen, denominada Cadernos Paraibanos de Antropologia e Sociologia, da qual éramos colaboradores, e que, após cerca de seis números, não teve continuidade.

Vinculada ao DCS, desde 1979, e ao MCS, mais tarde denominado Programa de PósGraduação em Sociologia - PPGS, a formação acadêmica de Simone deu-se no curso de História, enveredando depois pela antropologia, com a realização de sua pós-graduação (mestrado e doutorado) na UnB, com base nas pesquisas dedicadas à antropologia da pesca. Seus estudos pós-doutorais foram realizados em um laboratório de pesquisas interdisciplinares, denominado Núcleo de Pesquisa sobre Populações Humanas em Áreas Úmidas Brasileiras - Nupaub-USP. Nesse mesmo período, Simone aproxima-se de outro expoente da antropologia, Antonio Carlos Sant'anna Diegues. Nos idos de 1990, a pesquisadora navega em mares mais distantes, o que decisivamente marcou sua biografia como intelectual, como professora visitante na Universidade de Laval, Québec, Canadá, que possibilitou o diálogo com um antropólogo de importância ímpar na antropologia "haliêutica" (Breton, 1981). Neste período de estadias acadêmicas em ambas as instituições, a pesquisadora consolida-se como nome incontornável quando se fala de antropologia da pesca no Brasil.

\section{DA PRAIA PARA O MAR: UM BREVE CIRCUITO COM OS PESCADORES E SEUS SEGREDOS}

A antropologia da pesca ou antropologia marítima constituiu o campo de estudo escolhido, sendo na época pouco visível, por se apresentar teoricamente dissolvido em meio aos estudos do campesinato (Forman, 1970; Breton; Labrecque, 1982), o que levou Simone a buscar outra opção teórica para reconhecer e valorizar a singularidade da cultura marítima (Maldonado, 1988). A leitura dos argonautas de Malinowski (1976) certamente teria influenciado esta visão dos pescadores a partir do mar, diferentemente dos pescadores ribeirinhos, mais próximos do mundo campesino. Trata-se de um nicho privilegiado da antropologia, caracterizado por atrair um número restrito de pesquisadores no Brasil até os anos 1970, quando ela começou a realizar suas primeiras investidas etnográficas em comunidades pesqueiras, no litoral paraibano.

A antropologia da pesca analisada por Simone apresenta uma perspectiva diferente do que havia até então sobre os pescadores nordestinos. Dois estudos etnográficos de Câmara Cascudo, Jangada (1957) e Jangadeiros (1957), buscaram inserir os pescadores nordestinos em uma 
classificação específica de jangadeiros para distingui-los de outros pescadores, como os caiçara do litoral sul e sudeste brasileiro, pelo uso da jangada. Este bote típico da região, tão presente na paisagem das praias nordestinas de outros tempos, foi investigado como invenção construtiva de toros de madeira flutuante com uma singular vela triangular. Seguindo os passos de Simone no caminho percorrido junto aos pescadores paraibanos, vamos detectar a especificidade do seu percurso analítico, que vislumbra o mundo da pesca fora dessas especificidades locais ou regionais.

Para uma análise da produção bibliográfica, destacamos livros que teriam se transformado de alguma forma em clássicos da antropologia da pesca, os quais resultaram de pesquisas de mestrado e doutorado sucessivamente, Pescadores do Mar (1986) e Mestres \& Mares: espaço de indivisão na pesca marítima (1993). Ambos foram publicados por editoras do sul do país, incluindo segundas edições, o que demonstra a inserção nacional. Roque Laraia, no prefácio do segundo livro, fez um breve levantamento dos estudos sobre a pesca artesanal no Brasil e sobretudo no Nordeste, para constatar a escassez de pesquisas nessa área. Embora ele não tenha afirmado, consideramos que esta constatação a qualificaria como pioneira, e este livro, uma referência para a pesca no litoral nordestino. Esta constatação pode ser confirmada pela abundância de referências e citações a esses livros em estudos sobre a pesca no âmbito das ciências sociais em todo o Brasil.

Para discorrer sobre sua construção teórica em torno do pescador como categoria analítica central, ela relativizou o modelo classificatório que associa a atividade de pesca ao campesinato, ou como uma subcategoria denominada campesinato marítimo, por se tratar de uma produção tradicional (Maldonado, 1988). Superando essa indiferenciação de base, escapou do modelo classificatório vigente para investir no modo de ser dos pescadores, de onde extraiu outro critério. Ou seja, a especificidade da identidade do pescador resultava da sua relação com o ambiente marinho ou o mar (Maldonado, 1988). Em sua reflexão, considera indispensável levar em conta não só a relação do pescador com o ambiente, como seu comportamento diante dele. O primeiro aspecto destacado é relativo ao perigo ou aos riscos da pesca marinha, seja pelas condições do tempo para o navegante, seja pelo caráter extremamente perecível do peixe, obrigando o pescador a uma comercialização rápida que reduz seu poder de negociação, e ainda sobre a imprevisibilidade quanto à disponibilidade dos estoques pesqueiros. Estas seriam condições presentes em comunidades pesqueiras de todas as partes do mundo, que dependem do conhecimento do comportamento do mar, dos peixes, com a localização dos bancos de peixe, e das condições do mercado, como aspectos definidores da identidade do pescador (Maldonado, 1988). Para esta análise abrangente do pescador, Simone se valia de pesquisas bibliográficas em publicações internacionais de forma frequente para fundamentar sua interpretação dessa cultura.

$\mathrm{Na}$ busca de delimitar um campo específico da antropologia da pesca a partir da relação pescador e mar, emerge a categoria de território, tão precisa para a comunidade campesina, quanto 
indeterminada ou indivisível para os marítimos. Contudo, as formas assumidas por esses territórios baseiam-se na divisão entre mares e botes, que definem a cultura marítima, e não pertence a pescadores específicos em seus respectivos lugares, mas se reproduz com algumas regularidades e traços comuns entre pescadores de diferentes latitudes da terra, da Escandinávia ou do Canadá (Maldonado, 1988). A cultura marítima se manifesta, segundo Maldonado (1988), não apenas no âmbito da pesca artesanal, como também da pesca industrial, por assimilar traços desta mesma cultura.

Como bem enfatizado anteriormente, Simone busca outra via para compreender a produção econômica em comunidades pesqueiras do Nordeste, sintonizando-se em certa medida nas tipologias construídas por Diegues (1983). Sem dúvida, a pesca no Nordeste vinha sofrendo processos intensos de transformação no âmbito da produção, o que fazia com que, de certo modo, o cenário descrito por Cascudo (1957) ficasse congelado no tempo. As mudanças na esfera da tecnologia (introdução do motor no bote, o nylon, o gelo) incidiram de forma radical nas formas de sociabilidades nas práticas da pesca artesanal e no modo como os atores sociais se articulam e produzem sentidos. Essa tensão entre tecnologia e técnica é extensamente discutida pela antropóloga em sua obra Mestres e Mares, na qual esquematiza como esses processos técnicos afetam a ordem, a hierarquização e produção, tanto na terra como no mar.

Como produto do seu pós-doutorado no NUPAUB-USP, participou de um livro organizado por Diegues, intitulado Imagens das Águas (Diegues, 2000), dedicado aos estudos a respeito das imagens e do simbolismo evocados pelas águas dos mares, rios e ilhas, revelando sua integração a uma rede de pesquisadores brasileiros da área da pesca, não apenas da USP como de outras instituições do país. Ela contribuiu com dois capítulos, no primeiro "A caminho das pedras...", no qual fez novas reflexões relativizando a indivisibilidade do espaço marítimo, trazendo novos elementos como a mobilidade dos recursos explorados pelo pescador, como fator que impõe a delimitação de territórios ou zonas de pesca, o espaço marítimo é visto dividido em "mares" que recebem denominações específicas dos pescadores, “zonas de pesca", "pesqueiros", “pedras" (Maldonado, 2000, p. 62), que servem para demarcar e sinalizar áreas produtivas com pescados abundantes. Porém ela não encontra padrões para estas demarcações, nem mesmo com base na sazonalidade e nos ciclos reprodutivos naturais dos peixes, uma vez que, segundo os pescadores, pontos desaparecem e novos pontos são descobertos. Considerando as respostas evasivas dos pescadores, conclui-se que o conhecimento desses mares ou zonas de pesca é uma construção mental guardada como segredo. Embora esse primeiro texto aborde a percepção, o tema do segundo texto já se mostra configurado aí. Com o título "No mar: conhecimento e produção", emerge a relação entre conhecimento e etnoconhecimento, em que considera esta abordagem, embora com as devidas ressalvas de uma antropóloga quanto às tendências biologizantes nela contidas. 
Em "Botes e Tripulações de Iguais: ideário e instrumentos de trabalho na pesca marítima" (Maldonado, 2011), contribuição à coletânea organizada por Lisabete Coradini e Francisca Miller (uma das autoras deste ensaio) (Coradini; Miller, 2011), Simone reflete sobre a articulação da cultura material de pescadores da costa nordeste do Brasil em termos do seu nível de desenvolvimento produtivo. A análise é perpassada também pela questão simbólica e pela atribuição de valores e de um léxico específico dos coletivos pesqueiros marítimos ao seu trabalho no mar, incluindo os instrumentos que utilizam para tal. $\mathrm{O}$ texto se faz preceder de uma resenha bibliográfica sobre a antropologia e as culturas marítimas com a nova paisagem urbana.

A dimensão da cultura marítima dos pescadores que provocou mais estranhamento foi, sem dúvida, a do segredo que se refere ao conhecimento da localização dos bancos de peixe, e os sistemas de marcação, ou o "caminho das pedras". No entanto, com o advento de tecnologias que se popularizaram, como o GPS para localização dos cardumes, esta expertise dos pescadores ficou ameaçada com a perda da importância do segredo. Porém, o interesse pelo segredo acompanhou sua trajetória acadêmica daí em diante, e, após publicar várias traduções de textos de Simmel, com notas e comentários, na revista Política \& Trabalho, do PPGS, publicou o livro intitulado Georg Simmel: sentidos, segredos (2012).

As dificuldades materiais e os conflitos socioambientais vividos pelos pescadores artesanais foram sensíveis à Simone, que procurou apoiar movimentos como a Pastoral dos Pescadores, criado em 1968 pela Igreja Católica em Olinda- $\mathrm{PE}^{4}$, tendo participado de reuniões e manifestações em favor de coletivos de pescadores. Por outro lado, o reconhecimento de sua expertise no campo pesca da cultura marítima, fez com que ela fosse convidada para participar de equipes multidisciplinares para elaboração de relatórios de impacto ambiental, entre eles um realizado no Porto de Pecém, em Fortaleza. Outras participações teriam ocorrido no âmbito da Paraíba, integrando equipes de pesquisadores das ciências biológicas, em consultoria para projetos de intervenção na zona marinha que poderiam provocar danos às comunidades pesqueiras. Estas informações um tanto imprecisas decorrem de lembranças de conversas com ela e de encontros fortuitos em corredores dos departamentos das ciências biológicas, já que ela não tinha a preocupação de registrar na plataforma Lattes os importantes trabalhos técnicos dos quais participou.

Ela começa em fins de 1990 a olhar para novos fenômenos da cultura, como a cybercultura, abrindo um novo campo de observação, o das redes sociais. Publicou artigos com resultados de sua pesquisa, assim como experiências rituais virtuais, como a da Chama Violeta (2000), e orientou dissertações e teses em torno da cybercultura. Esta mudança de interesse revela a marca de Simone,

\footnotetext{
${ }^{4} \mathrm{O}$ movimento da Pastoral da Pesca foi criado por Dom Helder Câmara que expandiu depois para outros estados, incluindo a Paraíba.
} 
de navegar por campos pouco explorados, que oferecem novas janelas para outros mundos, como o que representou o mar e seus argonautas ao longo de sua trajetória.

\section{INGRESSANDO COM SIMONE NA ANTROPOLOGIA MARÍTIMA}

Na condição de aluno do PPGS ${ }^{5}$ da UFPB, em meados dos anos 2000, tive o primeiro contato com Simone Carneiro. Foi uma alegria conhecê-la pessoalmente, dado que já havia lido alguns textos dela. Na época, estava dedicado a pesquisar as mediações entre ribeirinhos e manguezal em Bayeux, na Paraíba, e essa interlocução com ela foi fundamental para pensar novas formas de abordar meu objeto. Encontrei Simone novamente em 2009, já no Doutorado e a convidei para orientar-me na ocasião. Naquele momento, Andrea Ciacchi estava na condição de orientador, contudo ele moveu-se para São Paulo e, por condições externas, abdicou da orientação. Simone sempre foi uma vigorosa orientadora e amiga. Atenciosa, convidou-me a ingressar no campo da antropologia marítima: na verdade, eu me convidei e ela rapidamente acatou. Fiz meu campo no litoral sul do Rio Grande do Norte e resultou numa tese sobre memória, territorialidade e a inovação tecnológica no âmbito da pesca. Aprendi muito com Simone: a generosidade intelectual aliada a uma honestidade teórica sem freios. Objetiva, direta e sem rodeios, rimos muito durante as orientações. Deixou-me livre para singrar os mares teóricos e recolher na minha rede de ideias, uma etnografia feita sob meu espectro como pesquisador.

No âmbito das atividades acadêmicas, participou de dezenas de bancas de conclusão de graduação, mestrado e doutorado em universidades da região e de fora sobre temáticas relacionadas à pesca. Apontam-se dois relevantes trabalhos orientados por Simone no MCS na área de especialização dela, que é a pesca, de Maria Ivete do Nascimento Arcanjo (1993) e Carlos Alberto Mororó Silva (1992), versando sobre cultura e articulação política de populações costeiras no Brasil. Tomando como norte o Lattes da antropóloga, infelizmente deixado de ser preenchido em 2011, informa que orientou dezoito pesquisadores a nível de mestrado, contudo não poderia deixar de registrar as duas orientações de 2012 em andamento, entre as quais me incluo. As duas teses de doutorado em andamento, no âmbito da antropologia da pesca foram defendidas: Rubens Elias da Silva, dedicado à pesca no litoral sul potiguar (Silva, 2012) e Gekbede Targino, mulheres e pesca artesanal na reserva extrativista nos litorais sul pernambucano e paraibano (Targino, 2012).

A criação em 2007 da reserva extrativista de Acaú no litoral sul da Paraíba representou uma conquista dos pescadores artesanais que contrasta com a chegada do turismo nas praias do litoral nordestino provocando mudanças significativas na vida dos pescadores que se inseriram de forma subalterna a esta atividade, especialmente as mulheres, como forma de compensar as perdas com a

\footnotetext{
${ }^{5} \mathrm{O}$ uso da primeira pessoa nesta subseção do ensaio reflete a experiência pessoal vivida por um dos autores na condição de orientando de Simone Maldonado.
} 
pesca e continuarem seus vínculos com o mar. Este fenômeno foi acompanhado por Simone através de duas dissertações orientadas por ela nos anos 1990, que marcaram o início desta mudança em praias que se tornaram ícones do turismo litorâneo nordestino: Pipa, no Rio Grande do Norte (Paiva, 1997), e Jericoacoara, no Ceará (Fonteles, 1998). Com as novas demandas da pós-graduação, ela definiu sua linha de pesquisa em torno dos novos fenômenos que envolvem sobretudo o meio terra, como o turismo, sistemas tradicionais de terapias envolvendo o uso medicinal de espécies da fauna e flora marinhas, como também o meio mar como a maricultura e o direito do mar.

As primeiras leituras que fiz dessa obra Mestres \& Mares $^{6}$ causaram-me um misto de admiração e respeito pela orientadora e amiga: o rigor heurístico, o zelo formal e a riqueza dos detalhes etnográficos. Sua etnografia é um retrato esboçado e bastante tenaz que descreve as dificuldades de burilar-se como intelectual e mulher num espaço ordenadamente dominado por homens, em duas instâncias distintas: na academia e no contexto de pesquisa de campo. Folheando calmamente, Mestres \& Mares, é possível compreender as limitações a que são impostas às mulheres via relações de gênero (Heilborn; e Sorj, 1999). As dificuldades de acesso aos pescadores, os liames presentes nas relações entre pescadores e seus familiares e, principalmente como a construção dos afetos tocaram a todos os envolvidos na etnografia traz um caráter excepcional ao trabalho de campo da antropóloga.

\section{A TESSITURA DA ETNOGRAFIA: ESTAR NO MUNDO E VER DA PERSPECTIVA DE GÊNERO}

Para uma narrativa sobre a tessitura da etnografia de Simone Maldonado, partimos dos interesses pessoais e de investigação que externalizam seu vigor de pensamento e rigor de uma exímia etnógrafa. Sendo uma antropóloga hard, oriunda da cepa da geração dos anos 1970, ela vem de uma formação em História, o que permitiu um olhar espectral e ao mesmo tempo de longa duração em suas análises antropológicas. Podemos inferir, a partir da afirmação acima, que essa peculiaridade a fez abordar uma análise antropológica diacrônica, compreendendo as práticas sociais da pesca no continuum tempo passado e tempo presente e as implicâncias nas transformações na esfera da pesca artesanal. Simone sempre foi avessa a modismos acadêmicos ou pesquisar o que estava na onda do momento. Tanto que, na segunda parte dos anos setenta, a historiadora envereda no mestrado em antropologia pela Universidade de Brasília, onde se debruça a estudar o que hoje convencionamos chamar de antropologia dos alimentos, mas já situada no campo da pesca artesanal. Ela buscou compreender, numa perspectiva culturalista, os modos alimentares de uma sociedade costeira no município de Cabedelo, na Paraíba, e as gramáticas que criam valores, normas e interdições acerca dos alimentos, atores sociais e grupo social. As complexas relações ou intercambiações entre atores

\footnotetext{
${ }^{6}$ Livro originário da tese "Em dois meios, em dois mundos", defendida por Simone Carneiro Maldonado em 1991. 
sociais, grupos sociais e os valores axiológicos que movem as tomadas de decisão daqueles são o ponto nodal das preocupações intelectuais da antropóloga em toda a sua trajetória como pesquisadora ciosa para compreender - no sentido estritamente weberiano - os problemas do seu tempo.

Entre Terra Liberta (1979) e Em dois Meios, Em dois Mundos (1991) há um hiato de quase quinze anos, entre mestrado e doutorado, em que ela deixa a dieta alimentar dos pescadores para compreender as bases da territorialidade produtiva em que se organizam a pesca que se fundamenta e se estrutura através da capacidade náutica dos pescadores (a marcação), da organização hierárquica do trabalho (mestrança) e da existência de uma dinâmica específica de controle e de distribuição da informação, a que se tem chamado de segredo, entre outros.

Estas temáticas, cuja existência e expressão empírica são a base de sua análise, a remetem teoricamente à sociologia alemã do início do século, sobretudo às obras de Georg Simmel e de Max Weber, ou seja, o que orientou suas reflexões sobre a pesca, foi, em primeira instância, a sociologia do segredo iniciada por Simmel (1906 e 1950) e solidificada por muitos estudos das sociedades que se utilizam dos seus pressupostos. As teorias de Simmel sobre a distribuição da informação como fundamento da sociedade e sobre o segredo como noção mais importante desse processo estão embutidas na sua teoria da sociedade, a teoria do conflito. Esta teoria e sobretudo os seus pressupostos informaram a análise dos comportamentos secretos de que trata a antropóloga ao falar do modo como os pescadores distribuem socialmente a informação, construindo tradições e formas de territorialidade no mar.

Da teoria da ação social de Weber vem a análise feita pela antropóloga das formas de dominação que envolvem as relações de poder e que, na pesca, informam a hierarquia e a organização do trabalho, expressando-se na construção social dos mestres da pesca e de navegação nos termos da dominação patriarcal. No percurso em que a antropóloga se aproxima dos trabalhos de Simmel sobre o segredo, paulatinamente, também a leva a incorporar várias das contribuições teóricas daquele autor. No caso da pesca, os conceitos de ocultação e de revelação, de hierarquia e de igualdade, de indivisão e de territorialidade, de confiança e inconfidência se cruzam na constituição de uma forma social (Maldonado, 1993).

Certamente eram outros tempos: o intelectual precisava de tempo subjetivo para construir-se pesquisador, experiência na docência, debates entre colegas e alunos sobre correntes de pensamento e problemas da contemporaneidade. Era imperativo respeitar o tempo da construção como intelectual, e Simone sempre respeitou isso. Sem dúvida, reflete-se nesse hiato. Diferentemente dos tempos atuais, em que, para pesquisadores, condicionados pelas mais diversas variáveis institucionais e escolhas pessoais, o título de doutor tornou-se uma necessidade urgente. Mas esse tempo de maturação trouxe seus benefícios para leitores e pesquisadores nas Ciências Sociais: Simone pesquisa, em seu Doutoramento em Antropologia, os processos de construção do espaço na pesca e 
a categoria de indivisão como intrínseca a critérios objetivos para compreender a atividade de produção na pequena pesca no nordeste brasileiro e como essa díade possibilitou mudanças radicais no mundo objetivo - tecnologias da/na pesca - e na esfera subjetiva - a mestrança como categoria fundamental na hierarquia pesqueira. Sendo assim, a autora sempre distribuiu e concebeu a construção do mundo social da pesca entre mundo material e mundo imaterial, esfera objetiva e esfera subjetiva, marcadamente uma intelectual influenciada pela sociologia formal de Georg Simmel.

Manejando autores das mais diferentes correntes antropológicas, Simone na obra Mestres \& Mares toma parte das discussões da antropologia sueca acerca de ethos e valores, a antropologia americana e a produção de espaços e, notadamente, a francesa. Nessa última, é necessário pontuar a forte influência da corrente neomarxista na antropologia de Maurice Godelier (1973), que em muito contribuiu na construção de Simone como antropóloga interessada na economia das sociedades de pequena escala. Dito isso, Simone inaugura uma antropologia interessada na produção da vida material, constituição da vida em contextos de comunitariedade e a dimensão ideológica que orienta as ações dos atores em situações da vida concreta. Essa preocupação sempre esteve presente inclusive nos encontros com orientandos e seu fatalismo otimista.

Inquietações pessoais e dificuldades em campo, extensamente narradas em Mestres \&Mares, torna a narrativa etnográfica de Simone um testemunho de uma época histórica que nos insiste em assombrar: os diferentes papéis que se intercalam na trajetória feminina em luta para a consolidação em espaços de dominação masculina: a ordem social da pesca na Paraíba. Simone expõe essas dificuldades em dialogar, fazer-se exprimir e construir pontes entre os diversos atores envolvidos na situação de campo o que torna sua obra um marco não apenas sobre o que a antropologia descreve como "a perspectiva do outro", mas inclusive sobre a perspectiva de "nós" no espaço de outros (Clifford, 2011), o que causa “deslocamento permanente entre a própria identidade, o 'eu' e a identidade de outros" (Grossi, 1992, p. 12) e como esse deslocamento é viabilizado por diferentes marcadores sociais de gênero em contexto de campo.

Tomando como referência os escritos de Heilborn e Sorj (1999) e Grossi (1992), a inserção de mulher no universo masculino, onde vigoram as lógicas da masculinidade hegemônica e suas intercessões de poder, não passaria impune. Silêncios, omissões, enunciados e palavras ao meio foram estratégias bem descritas pela antropóloga em seus escritos sobre o campo e como isso a afetou como mulher e subjetividade.

É importante frisar as intensas relações entre mulheres nessa construção como pesquisadora e antropóloga, sua admiração e cumplicidade com antropólogas em sua estada em Brasília, como Ellen Fensterseifer Woortmann e Mireya Suárez y Suárez. Inaugurava-se ali, nos anos setenta, uma antropologia marcadamente feminina, que teve Simone como um dos expoentes no Nordeste. 
A despeito deste texto, podemos pensar como o campo em questão teve contribuições incontestáveis da assinatura feminina, quais sejam: Gioconda Mussolini, escrevendo e tipificando a pesca caiçara no litoral paulista e a contribuição dela no campo tão bem descrito por Ciacchi (2015), no campo da pesca caiçara e música, dentre outras no sudeste brasileiro. Lourdes Gonçalves Furtado (1987), Violeta Refkalefsky Loureiro (1985) e Maria Eunice Soares Penner (1980), apenas para citar essas no campo de estudo na pesca amazônica. De todo modo, as trajetórias femininas no campo da pesca é uma área interessante de pesquisa e que merece um olhar atento para compreender como essas trajetórias se interceptam e criam sentidos tanto na contribuição antropológica quanto na construção de identidades de pesquisadoras, possibilitando a inserção de novas pesquisadoras na área, nas décadas seguintes.

É importante frisar que a escrita etnográfica de Simone transcende ou mesmo ignora pontualismos dessa relação entre antropólogos e o que categorizamos "o outro". Sem perder a precisão da palavra, bem justaposta a cada parágrafo de sua escrita, Simone traz emoção ao texto escrito. Esse traço estilístico derruba as fronteiras entre aquilo que se vê e descreve e o que sentimos nas mediações com outros atores. No final de Mestres \& Mares, Simone conta sobre a morte de um pescador no mar. Ao leitor, fica facultada a condição de se colocar como "humano" e traduzir subjetivamente processos de construção da empatia. A morte descrita ali borrifa as fronteiras descritas anteriormente e coloca a antropóloga como "pessoa" que não apenas descreve, mas sente.

A produção bibliográfica da antropóloga é multifacetada, posto que exprime a versatilidade de uma pesquisadora multidisciplinar. Dentre os quinze artigos publicados em periódicos, três são dedicados à pesca. Os outros ou se dedicam a estudar extensamente o pensamento simmeliano ou o desdobramento das reflexões deste no mundo atual marcado pela infiltração da internet na vida cotidiana. Dentre os três livros publicados, dois marcam sua trajetória como antropóloga dedicada a entender a cultura pesqueira nordestina: Pescadores do Mar (1986), livro dedicado a descrever a pesca marítima sem a pretensão de ser erudito e exclusivista: de leitura agradável e de fácil acesso para iniciantes. Mestres \& Mares, de (1993), evidencia uma antropóloga no auge de sua produção de pensamento, consolidando-se como magnum opus e, com isso, pode ajudar a compreender o universo da pesca no Nordeste brasileiro, desnaturalizando-a e retirando o véu de uma recorrente representação social que a retrata como idílica e imutável.

\section{REFERÊNCIAS}

ARCANJO, Maria Ivete do Nascimento. Homens e Peixes: o tempo na pesca artesanal. Mestrado em Mestrado em Ciências Sociais. Universidade Federal da Paraíba, UFPB, Brasil. (Dissertação). João Pessoa, 1993. 
BRETON, Yvan. L'anthropologie sociale et les sociétés de pêcheurs: réflexions sur la naissance d'un sous-champ disciplinaire. Revue L'Anthrologie et sociétés, 5 (81), p. 7 - 27. Acesso em 16 de maio de 2020. Link para acesso: http://www.erudit.org/revue/as/1981/v5/n1/000987ar.pdf

BRETON, Yvan; LABRECQUE, Marie F. La pêche, l'agriculture et l'artisanat à la paysannerie maya. Québec: Les Presses de L’Université Laval, 1982.

CASCUDO, Luís da Câmara. Jangada: uma pesquisa etnográfica. Rio de Janeiro: MEC, 1957.

CASCUDO, Jangadeiros. Rio de Janeiro: Serviço de Informação Agrícola, 1957.

CIACCHI, Andrea. Do desembarque do navio ao embarque na canoa: Gioconda Mussolini, 18861938. Revista de Antropologia, São Paulo, 58 (2), 69-98, 2015. DOI: https://doi.org/10.11606/21790892.ra.2015.108512

CLIFFORD, James. A experiência etnográfica: antropologia e literatura no século XX. GONÇALVES, José Reginaldo Gomes (org.). Rio de Janeiro: EDUFRJ, 2011.

CORADINI, Lisabete; MILLER, Francisca. Imagem e Meio Ambiente: debates atuais. Natal: Edufurn, 2011.

DANTAS, Simone Carneiro. Terra liberta: hábitos alimentares em Ponta de Mato, (Dissertação). Mestrado em Antropologia / UnB. Brasília, 1979.

DIEGUES, Antonio Carlos Sant'anna. Pescadores, camponeses e trabalhadores do mar. São Paulo: Ática, 1983.

DIEGUES, Antonio Carlos Sant'anna (org.). Imagem das águas. São Paulo: Hucitec. 2000.

FONTELES, José Osmar. Turismo e o cotidiano dos moradores de Jericoacoara - Ceará. Dissertação (Mestrado em Programa de Pós Graduação em Ciências Sociais) Universidade Federal da Paraíba, 1998.

FORMAN, Shepard. The raft fishermen: tradition and change in the brazilian peasant economy. Indiana Press / Bloomington \& London, 1970.

FURTADO, Lourdes Gonçalves. Curralistas e Redeiros de Marudá: pescadores do litoral do Pará. Belém: CNPq e Museu Paraense Emílio Goeldi, 1987.

GODELIER, Maurice. Horizontes da Antropologia. Lisboa: Edições 70, 1973.

GROSSI, Miriam Pilar. Na busca do "outro" encontra-se a "si mesmo". In: Grossi, M. P. (org.). Trabalho de campo \& Subjetividade. Florianópolis: PPGAS - UFSC, 1992, p. 7 - 18.

HEILBORN, Maria Luiza; SORJ, Bila. Estudos de gênero no Brasil. Miceli, Sérgio (org.). O que ler na Ciência Social brasileira (1970 - 1995). Sociologia (Volume II). São Paulo: Editora Sumaré ANPOCS / Brasília: CAPES, 1999, p. 223 - 236.

LOUREIRO, Violeta Refkalefsky. Os parceiros do mar: natureza e conflito social na pesca da Amazônia. Belém: Cnpq - Museu Emílio Goeldi, 1985.

MALDONADO, Simone Carneiro. Pescadores do Mar. São Paulo: Editora Ática, 1986.

MALDONADO, Simone Carneiro. Antropologia Marítima, Comunicação e Cultura. Cadernos Paraibanos de Antropologia e Sociologia. vol. 4., p. 267-279, 1988.

MALDONADO, Simone Carneiro. Em dois meios, em dois mundos: a experiência pesqueira marítima. Tese de doutorado. Programa de Pós-Graduação em Antropologia Social, UnB, Brasília. 202 p. 1991.

MALDONADO, Simone Carneiro. Mestres \& Mares: espaço e indivisão na pesca marítima. São Paulo: Annablume, 1993. 
MALDONADO, Simone Carneiro. Dois Excertos de Georg Simmel. Política \& Trabalho. $\mathrm{n}^{\mathrm{o}}$ 14, $\mathrm{p}$. 173-175, 1998.

MALDONADO, Simone Carneiro. Breve incursão sobre a sociologia do segredo. Política \& Trabalho, no 15, p. 217-220, 1999.

MALDONADO, Simone Carneiro. A caminho das pedras: percepção e utilização do espaço da pesca simples. In: Diegues, Antonio Carlos (org.) A imagem das águas. São Paulo: Hucitec, p. 5967, 2000.

MALDONADO, Simone Carneiro. No mar: conhecimento e produção. In: Diegues, Antonio Carlos (org.) A imagem das águas. São Paulo: Hucitec, p. 95-100, 2000.

MALDONADO, Simone Carneiro. A chama dourada - Sociabilidade e religiosidade na internet. in: Miele, Neide; León, Adriano; Andrade, Maristela (orgs) O velho e o novo em mil anos. Religare, João Pessoa: Manufatura, p.131-138, 2000.

MALDONADO, Simone Carneiro. Botes e tripulações de iguais: ideário e instrumentos de trabalho na pesca marítima. In CORADINI, Lisabete; MILLER, Francisca. Imagem e Meio Ambiente: debates atuais. Natal: Edufurn, 2011.

MALDONADO, Simone Carneiro. Georg Simmel: sentido, segredo. Curitiba: Appris, 2012.

MALINOWSKI, Bronislaw. Argonautas do Pacífico Ocidental. São Paulo: Abril Cultural. 1976.

PAIVA, Ilnete Porpino de. Vendo coisas que nunca viu, vendo gente que nunca viu: Pipa turistificada. Dissertação (Mestrado em Programa de Pós Graduação em Ciências Sociais) Universidade Federal da Paraíba, 1997.

PENNER, Maria Eunice Soares. A dialética da atividade pesqueira no nordeste amazônico. (Dissertação). Recife: UFPE, 1980.

SILVA, Carlos Alberto Mororó. Colônia de Pescadores: a reprodução da dependência. Dissertação (Mestrado em Serviço Social). Universidade Federal da Paraíba, UFPB, João Pessoa, 1992.

SILVA, Rubens Elias da. Guiados por mares e peixes: memória social, inovação tecnológica e o processo de fragmentação na pequena pesca mercantil em duas comunidades costeiras no Rio Grande do Norte. Tese (Doutorado). UFPB / PPGS, João Pessoa, 2012. Link para acesso: http://tede.biblioteca.ufpb.br/handle/tede/7281

SIMMEL, Georg. The sociology of secret and of secret societes. American Journal of Sociology, Volume 11, Number 4 (1906). Link para acesso: https://www.journals.uchicago.edu/doi/10.1086/211418. Acesso em 04 de setembro de 2020.

SIMMEL, Georg. The secret and the secret society. New York: Free Press, 1950.

TARGINO, Gekbede Dantas. Sobre as águas: a tradição e a pesca artesanal em três comunidades da Reserva Extrativista de Acaú-PB Goiana-PE. Tese (Programa de Pós Graduação em Sociologia) Universidade Federal da Paraíba, 2012. 